\title{
Development of unilateral obstacle-avoiding mower for Y-trellis pear orchard
}

\author{
Xiaohui Lei ${ }^{1}$, Yannan $\mathrm{Qi}^{1}$, J in Zeng ${ }^{1}$, Quanchun Yuan ${ }^{1}$, Youhong Chang ${ }^{2}$, Xiaolan Lyu ${ }^{1^{*}}$ \\ (1. Institute of Agricultural Facilities and Equipment, Jiangsu Academy of Agricultural Sciences / Key Laboratory of Protected Agriculture \\ Engineering in the Middle and Lower Reaches of Yangtze River, Ministry of Agriculture and Rural Affairs, Nanjing 210014, China; \\ 2. Institute of Pomology, Jiangsu Academy of Agricultural Sciences / Jiangsu Key Laboratory for Horticultural Crop Genetic Improvement, \\ Nanjing 210014, China)
}

\begin{abstract}
To solve the problem of weeding under Y-trellis pear orchards, a unilateral obstacle-avoiding mower (UOAM) was developed in this study. The mower is composed of an obstacle-avoiding disc mechanism, a hydraulic profiling mechanism, and a cutting disc mechanism. The diameter of the obstacle-avoiding disc was $0.7 \mathrm{~m}$, which could swing around the trunk or ground pile actuated by the spring mechanism. The piston movement of the hydraulic cylinder controls the working position of the obstacle-avoiding disc. The maximum extension distance of the hydraulic profiling arm was $1 \mathrm{~m}$. Based on the national standards and actual situation of orchards, the optimum parameters were determined with a combination of advancing speed of $0.44 \mathrm{~m} / \mathrm{s}$, rotation speed of the cutting disc at $2000 \mathrm{r} / \mathrm{min}$, blade number of 2 , and cutting edge length of $0.2 \mathrm{~m}$. Finally, the design parameters were verified by the mathematical model of the blade cutting edge trajectory and multi-body dynamics simulation. Taking stubble cutting stability, leakage rate, working efficiency and costs as the test indexes, field performance comparison tests were carried out on the three operation modes of UOAM mowing, shoulder carrying mower (SCM) mowing and manual weeding. Test results showed that the coefficient variation of stubble cutting height of UOAM was the smallest, showing that the working stability of UOAM was better than the other two treatments. The leakage rate of UOAM was $2.42 \%$, and its coefficient variation was lower than that of SCM. The working efficiency of UOAM was much higher than that of SCM and manual weeding, which was 4.44 times of SCM and 20 times of manual weeding. The profitable area of UOAM was $7.02 \mathrm{hm}^{2}$, showing that it was suitable for large-scale mechanized Y-trellis pear orchards.
\end{abstract}

Keywords: unilateral obstacle-avoiding mower, Y-trellis pear orchard, movement trajectory, working performance DOI: $10.25165 /$ j.ijabe.20221501.7013

Citation: Lei X H, Qi Y N, Zeng J, Yuan Q C, Chang Y H, Lyu X L. Development of unilateral obstacle-avoiding mower for Y-trellis pear orchard. Int J Agric \& Biol Eng, 2022; 15(1): 71-78.

\section{Introduction}

Weeding is a requisite agronomic section in orchard management. Herbicide spraying not only destroys the ecological environment ${ }^{[1,2]}$ but also promotes weed resistance ${ }^{[3]}$. With the development of sod culture in orchards ${ }^{[4-7]}$, chemical weeding has been gradually replaced by mechanized mowing in recent years. In order to restrict overgrowth of weeds, the operator needs to cut them 4 to 5 times per year ${ }^{[8]}$. Mechanized mowing of an orchard is categorized into inter-row and intra-row mowing. Inter-row can easily be realized through rotary tillage or by inter-row mowers, however, intra-row mowing is still a difficult problem in the industry.

\section{Received date: 2021-08-23 Accepted date: 2021-12-07}

Biographies: Xiaohui Lei, Assistant Researcher, research interest: orchard management machinery and its application, Email: leixiaohui.2008@163.com; Yannan Qi, Research Assistant, research interest: orchard management informatization, Email: qiyn1020@163.com; Jin Zeng, Research Assistant, research interest: orchard bio-environment and energy engineering, Email: jinzeng@jaas.ac.cn; Quanchun Yuan, Assistant Researcher, research interest: orchard management machinery, Email: yuanquanchun@jaas.ac.cn; Youhong Chang, Researcher, research interest: orchard management machinery and its application, Email: cyh@jaas.ac.cn.

*Corresponding author: Xiaolan Lyu, Researcher, research interest: orchard management machinery and its application. Institute of Agricultural Facilities and Equipment, Jiangsu Academy of Agricultural Sciences, Nanjing 210014, China. Tel: +86-25-84390082, Email: 1xlanny@126.com.
The research of mechanized intra-row mowers in China started relatively late with just a few cases. Prototype research and development in China is mainly conducted in universities, mostly focusing on the innovative application of hydraulic obstacle-avoiding devices with sensor detection. Zhang et al. ${ }^{[9,10]}$ developed a scraper-type orchard intra-row weeding device based on computer modeling simulation and optimization. $\mathrm{Xu}$ et al. ${ }^{[11]}$ developed an automatic intra-row obstacle-avoiding mower for trellis grape orchard, achieving a coverage rate of field weeding of $98.1 \%$. Zhao et al. ${ }^{[12]}$ developed an orchard obstacle-avoiding rotary tiller, whose obstacle avoidance rate was $100 \%$ and the leakage rate was $3.58 \%$. Zhang et al. ${ }^{[13]}$ developed an obstacle avoidance system for orchard lawn mower based on binocular vision technology, whose measurement error was within $550 \mathrm{~mm}$ and the average positioning time was $2.99 \mathrm{~s}$. Lei et al. ${ }^{[14]}$ developed a unilateral combine orchard mower with sensor detection, whose working efficiency was $0.24 \mathrm{hm}^{2} / \mathrm{h}$. A common feature of these mowers is the use of the obstacle-avoiding device, which is expensive and whose sensitivity determines the performance efficiency of the device. At present, the technical maturity of obstacle-avoiding devices is still far from practical application and needs further research. Some developed countries have produced related products, however, the price of such devices is high, and they are mainly suitable for hedgerow-type orchards. In recent years, researchers are focused on new types of mowing robots and the performance evaluation of different mechanized weeding methods. Muhammad et al. ${ }^{[15]}$ 
developed a robotic lawnmower for small-sized pear orchards in Japan, which can control the growth of weeds for consecutive years. An intelligent robotic lawnmower is expensive and mainly suitable for flat road surface. Mia et al. ${ }^{[16,17]}$ studied the working performance of integrated and mechanized weeding in orchards, and the evaluation indexes include weed species diversity, soil coverage, weed biomass production, soil nitrogen status, and weed abundance. Martinelli et al. ${ }^{[18]}$ studied the effects between artificial grass planting and herbicides spraying on the citrus orchard. Granatstein et al. ${ }^{[19]}$ compared the effects of mechanical inter-row weeding, herbicide spraying and flame weeding in organic apple and pear orchards. China is still in the stage of developing efficient orchard mowers currently, and the performance evaluation methods of mechanized lawn mowers are the future research direction. The above evaluation methods can provide a reference for the performance optimization of orchard mowers.

Y-trellis cultivation is a modern planting pattern that originated from Korea which is suitable for the windy area and can realize the mechanization of orchard production ${ }^{[20,21]}$. In the early stage of orchard construction, weed barrier fabric is laid under the tree saplings to reserve water, fertilizers and facilitate weeding ${ }^{[22,23]}$. The service life of the weed barrier fabric is usually 3-5 years, so after it perished, the weed management under the tree is mainly based on shoulder carrying mower (SCM) mowing and manual weeding. In the production practice, due to the limitation of trellis space, semi-mechanized SCM mowing or manual weeding has low efficiency. In this study, a unilateral obstacle-avoiding mower (UOAM) for Y-trellis pear orchards was developed, which is useful for mowing intra-row weeds and saving labor force and costs.

\section{Materials and methods}

\subsection{Machine structure and working principle}

UOAM is linked with a tractor by a three-point suspension. The whole machine is composed of a body frame, a hydraulic profiling mechanism, a spring obstacle-avoiding mechanism, a hydraulic cutting disc and a limit wheel. The structure of the UOAM is shown in Figure 1. The tractor is equipped with a hydraulic output system to adjust the position of hydraulic profiling mechanism by controlling the hydraulic cylinder. The power of the cutting disc is provided by the hydraulic motor, which is driven by the tractor PTO (Power Take Off). The main structure and performance parameters of UOAM are shown in Table 1. When the UOAM is working, the tractor adjusts it to a suitable operating height by hydraulic lifting, then lays the profiling mechanism to a suitable position by driving the hydraulic cylinder; the hydraulic motor drives the cutting disc to rotate, finally, the tractor drives the mower forward. The S-shaped working path of UOAM in the field is shown in Figure 2.

The tractor PTO drives the gear pump to deliver the hydraulic oil to the hydraulic motor. The hydraulic motor drives the cutting disc to rotate to mow weeds. Two channels and two moving arms are welded on the front and rear mounted frames respectively, forming a parallelogram structure. The hydraulic cylinder is hinged above the parallelogram in the form of a diagonal line. The piston movement of the hydraulic cylinder controls the initial working position of the obstacle-avoiding disc. One end of the disc connecting rod is hinged with the disc fixed bracket. A spring mechanism is fixed inside the disc fixed bracket and the disc connecting rod can swing around the hinge point. The other end of the disc connecting rod is hinged with the center of the obstacle-avoiding disc, which can rotate freely around the hinged point. The cutting disc is installed below the obstacle-avoiding disc, and the rotation diameter of the cutting disc is less than that of the obstacle-avoiding disc. When the outer edge of the obstacle-avoiding disc touches a trunk or a ground pile, the disc connecting rod will swing around the obstacle under the action of the spring mechanism. A rubber ring is fixed around the outer edge of the obstacle-avoiding disc to prevent it from scraping the obstacle. A stiffener is welded at the top of the obstacle-avoiding disc, to enhance the structural strength of the disc. The limit wheel is used to prevent the bottom of the cutting disc from touching the ground and to ensure high working quality.

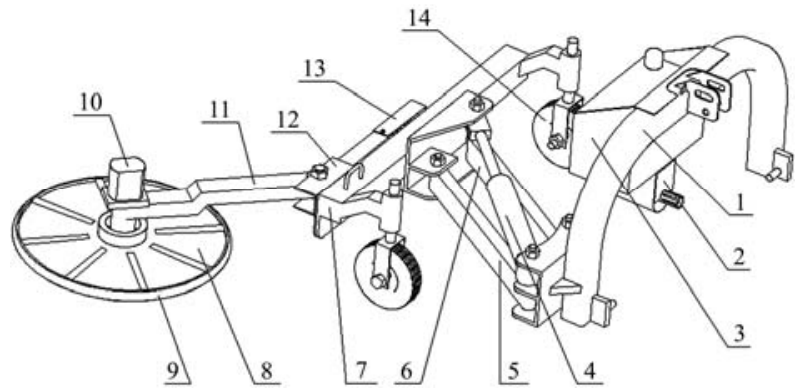

1. Front mounted frame 2. Gear pump 3. Hydraulic oil tank 4. Hydraulic cylinder 5. Left moving arm 6. Right moving arm 7. Rear mounted frame 8. Obstacle-avoiding disc 9. Rubber ring 10. Hydraulic motor 11. Disc connecting rod 12. Disc fixed bracket 13. Spring guard 14. Limit wheel Note: UOAM means unilateral obstacle-avoiding mower.

Figure 1 The structure of UOAM

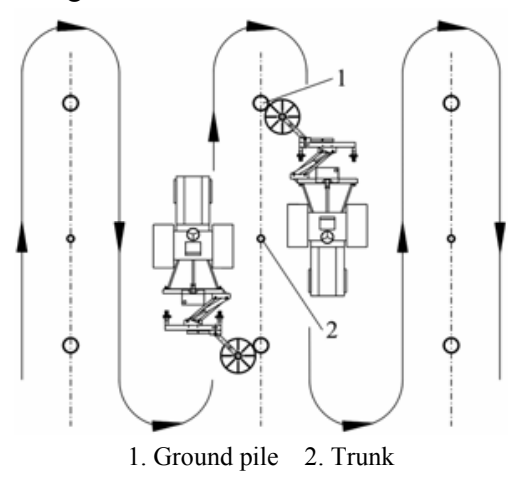

Note: Arrow signifies the turning direction of the mower.

Figure 2 Schematic of S-shaped working path of UOAM

Table 1 Main structure and performance parameters of UOAM

\begin{tabular}{lc}
\hline \multicolumn{1}{c}{ Parameter } & Value \\
\hline Tractor power $/ \mathrm{kW}$ & 36.8 \\
Weight $/ \mathrm{kg}$ & 211 \\
Size $($ length $\times$ width $\times$ height $) / \mathrm{m} \times \mathrm{m} \times \mathrm{m}$ & $1.6 \times 1.7 \times 0.7$ \\
Maximum extension distance of hydraulic profiling arm $/ \mathrm{m}$ & 1 \\
Advancing speed $/ \mathrm{m} \cdot \mathrm{s}^{-1}$ & 0.44 \\
Rotation speed of $\mathrm{cutting} \mathrm{disc} / \mathrm{r} \cdot \mathrm{min}^{-1}$ & 2000 \\
Blade number & 2 \\
Cutting edge length $/ \mathrm{m}$ & 0.2 \\
Cutting width $/ \mathrm{m}$ & 1.4 \\
\hline Note $:$ UOAM means unilateral obstacle-avoiding mower.
\end{tabular}

Note: UOAM means unilateral obstacle-avoiding mower.

\subsection{Design and analysis of key components}

Referring to the key design requirements of Y-trellis pear orchards ${ }^{[24]}$, the trees were planted with line spacing of $5 \mathrm{~m}$ and row spacing of $3 \mathrm{~m}$. To fit the growth of fruit trees, the Y-trellis structure was designed, as shown in Figure 3. Trellis height is $3 \mathrm{~m}$, height of the fixing rod is $0.5 \mathrm{~m}$, and the angle between the trellis plane and ground is $45^{\circ}$. The ground pile is made of PP 
pipe (diameter of $0.18 \mathrm{~m}$ ) filled with cement. To reduce soil corrosion to the steel tube, the top of the PP pipe is $0.2 \mathrm{~m}$ above the ground. The pear trees are 6 years old $(6$ a), and the average diameter of the tree trunks is $8 \mathrm{~cm}$.

To match the trellis structure ${ }^{[25]}$, a YCX-504D type tractor (manufactured by Yueda Group Co., Ltd., Jiangsu, China) was selected in this study, as shown in Figure 3a. The height of the driver is $1.7 \mathrm{~m}$. The distance between the top of the driver's head and the ground is $1.8 \mathrm{~m}$. When the driver's head is tangent to the trellis (the dotted line position in Figure 3a), the minimum distance between the longitudinal median plane of the tractor and the trunk $D_{1}$ is $1.3 \mathrm{~m}$.
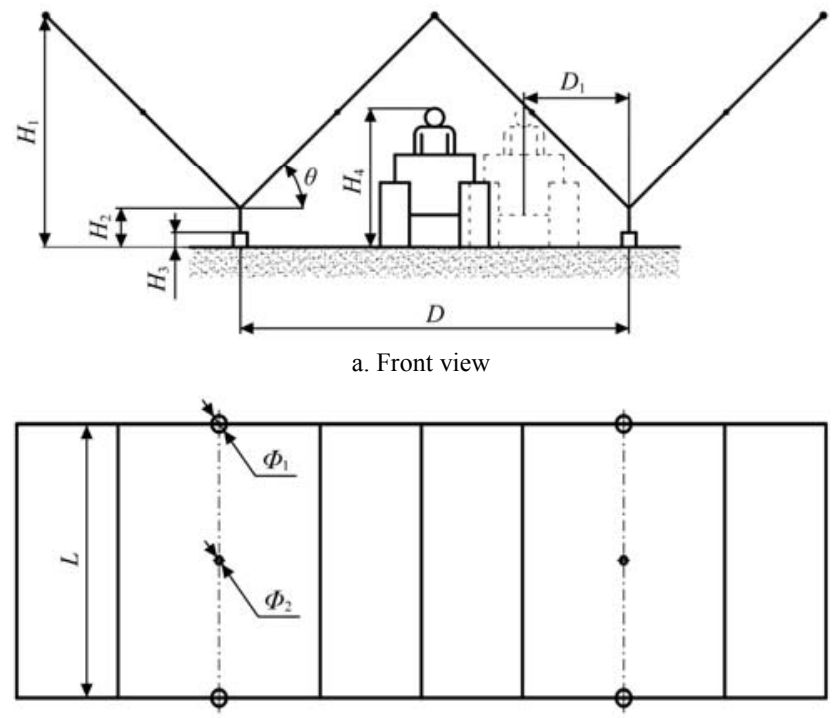

b. Top view

Note: $H_{1}$ is the trellis height, $\mathrm{m} ; H_{2}$ is the height of the fixing rod, $\mathrm{m} ; H_{3}$ is the ground pile height, $\mathrm{m} ; \mathrm{H}_{4}$ is the distance between the top of the driver's head and ground, $\mathrm{m} ; D_{1}$ is the minimum distance between the longitudinal median plane of the tractor and the trunk, $\mathrm{m} ; D$ is the line spacing; $\theta$ is the angle between the trellis plane and ground, $\mathrm{m} ; L$ is the row spacing, $\mathrm{m} ; \Phi_{1}$ is the diameter of ground pile, $\left({ }^{\circ}\right) ; \Phi_{2}$ is the diameter of trunk, $\left({ }^{\circ}\right)$.

Figure 3 Trellis structure of pear orchard

The structure of the UOAM in contraction and extension is shown in Figure 4. The diameter of the obstacle-avoiding disc is $0.7 \mathrm{~m}$ and the length of the disc fixed bracket is $0.2 \mathrm{~m}$. The hinge point between the disc connecting rod and the disc fixed bracket is at the middle of the disc fixed bracket. In order to shorten the length of the disc connecting rod and reduce the bending moment caused by the obstacle-avoiding disc, the leftmost end of the disc overlaps with the rightmost plane of the disc fixed bracket. Simple geometric calculation shows that the distance between the hinge points at both ends of the disc connecting rod in the horizontal direction $l_{1}=0.45 \mathrm{~m}$.

In the process of UOAM operation, the obstacle-avoiding disc is blocked now and then by trunks and ground piles. To avoid obstacles, the internal spring mechanism of the disc fixed bracket was designed, as shown in Figure 5. The front end of the disc connecting rod is hinged with the disc fixed bracket. The right end of the compression spring is thrust by the disc fixed bracket. A wire goes through the center of the compression spring, and the left end of the wire is in fixed connection with the bolt, which is in a threaded connection with the nut at the left end of the compression spring. The left side of the compression spring is thrust by the nut. After the wire bypasses the outer edge of the disc connecting rod, the right end of the wire is in fixed connection with the fixed block of the wire. The angle $\beta$ is adjusted by controlling the relative position between the bolt and the nut, so as to adapt to different working conditions.

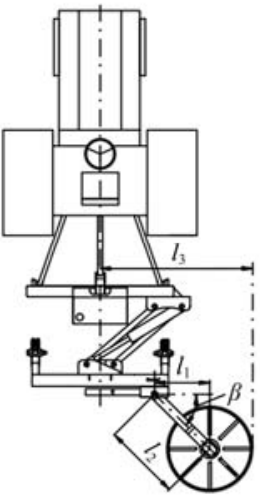

a. Contraction

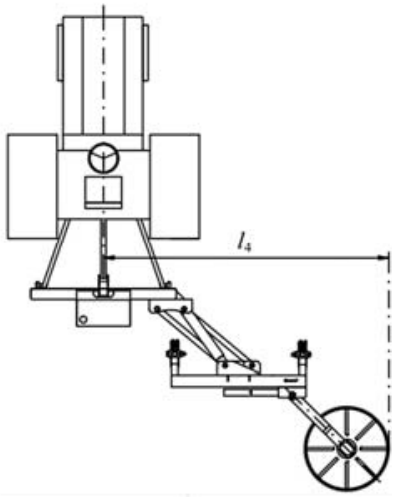

b. Extension
Note: $l_{1}$ is the distance between the hinge points at both ends of the disc connecting rod in the horizontal direction, $\mathrm{m} ; l_{2}$ is the distance between hinge points at both ends of the disc connecting rod, $\mathrm{m} ; l_{3}$ is the distance between the longitudinal median plane of the tractor and rightmost point of the obstacle-avoiding disc in contraction status, $\mathrm{m} ; l_{4}$ is the distance between the longitudinal median plane of the tractor and rightmost point of the obstacle-avoiding disc in extension status, $\mathrm{m} ; \beta$ is the angle between the disc connecting rod and the horizontal line in this figure in natural status, $\left(^{\circ}\right)$.

Figure 4 Structure of UOAM in contraction and extension status

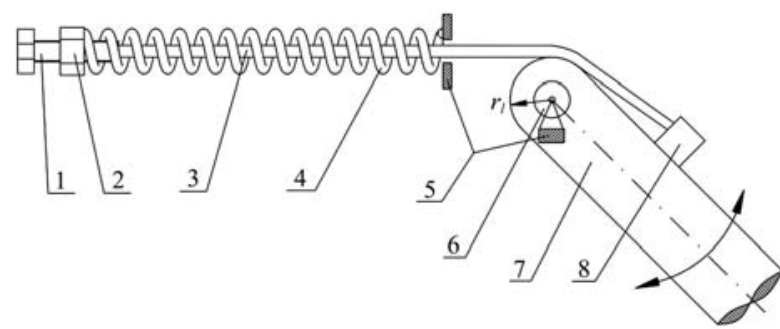

1. Bolt 2. Nut 3. Wire 4. Compression spring 5. Disc fixed bracket 6. Pin 7. Disc connecting rod 8. Fixed block

Note: $r_{l}$ is the arc radius at the front end of the disc connecting rod (equals to half of the width of the disc connecting rod). Arrows show the swing direction of the disc connecting rod.

Figure 5 Internal spring mechanism of the disk fixed bracket

When the obstacle-avoiding disc is blocked by an obstacle, the disc connecting rod rotates clockwise around the pin. When the obstacle-avoiding disc bypasses the obstacle, the disc connecting rod rotates counterclockwise around the pin and recovers the original state. To facilitate the adjustment, angle $\beta$ was designed to be $45^{\circ}$ and $l_{2}=l_{1} / \sin 45^{\circ}=0.64 \mathrm{~m}$. In Figure 5 , the pressure on the compression spring and the resistance from the obstacle meet the torque equilibrium condition. Rectangular square steel $(50 \mathrm{~mm} \times 70 \mathrm{~mm})$ was selected as the material of the disc connecting rod. The compression spring is cylindrical spring in $65 \mathrm{Mn}$ spring steel (shear modulus is $8 \times 10^{10} \mathrm{~Pa}$ ), with a wire diameter of $8 \mathrm{~mm}$ and mean coil diameter of $41 \mathrm{~mm}$, length of $0.3 \mathrm{~m}$ and active coil number of 15 . The spring stiffness satisfies Equation (1) ${ }^{[26]}$. After calculation, the spring stiffness $K=$ $39620 \mathrm{~N} / \mathrm{m}$.

$$
K=\frac{G d_{l}^{4}}{8 D^{3} n_{s}}
$$

where, $K$ is the stiffness of the spring, N/m; $G$ is the shear modulus, $\mathrm{Pa} ; d_{l}$ is the wire diameter, $\mathrm{m} ; D$ is the mean coil diameter, $\mathrm{m} ; n_{s}$ is the active coil number.

The working process of the obstacle-avoiding disc is shown in Figure 6. $O_{i} O_{i}{ }^{\prime}(i=1,2, \ldots, 14)$ and circles represent the positions of the disc connecting rod and obstacle-avoiding disc at different moments. $O_{1}{ }^{\prime} O_{7}{ }^{\prime}$ and $O_{8}{ }^{\prime} O_{14}{ }^{\prime}$ are movement trajectories of the 
front hinge point of the disc connecting rod. In the process of avoiding a ground pile, the obstacle-avoiding disc contacts with point 1 firstly, then, it turns around to point 2 and leaves the ground pile; the disc connecting rod is retracted within the area $\mathrm{O}_{2}{ }^{\prime} \mathrm{O}_{2} \mathrm{O}_{3} \mathrm{O}_{3}{ }^{\prime}$ under the effect of compression spring, then the obstacle-avoiding disc moves along the straight line $\mathrm{O}_{3} \mathrm{O}_{4}$. The obstacle-avoiding process on trunks is the same as that on ground piles.

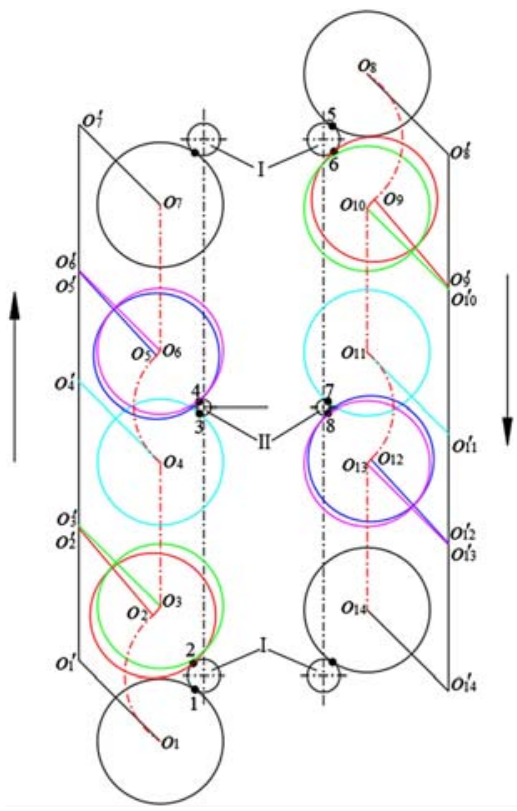

Note: I represents the trunk; II represents the ground pile. Arrows indicate the movement directions of UOAM. The two red dotted lines are the movement trajectories of the central point of the obstacle-avoiding disc and different colored circles represent the position of the obstacle-avoiding disc at different times.

Figure 6 The working process of the obstacle-avoiding disc

The position of obstacle-avoiding disc at different contact positions is shown in Figure 7. Figure 7a shows the working process of the disc when the first contact point (between the obstacle-avoiding disc and the obstacle) is at the midpoint of the $1 / 4$ arc on the right semi-circle of the disc. The outer edge of the obstacle-avoiding disc contacts the obstacle at point 7 and leaves at point 8 . The straight line where line segment $O_{16} O_{16}{ }^{\prime}$ is in passes through point 8 and the center of the disc, and $\beta_{1}=45^{\circ}$, at this time, the disc connecting rod does not need to be retracted. Figure $7 \mathrm{~b}$ shows the working process when the first contact point lies in the left of the $1 / 4$ arc midpoint. The outer edge of the obstacle-avoiding disc contacts the obstacle at point 9 and leaves at point 10. The center of obstacle-avoiding disc is closer to $O_{17}{ }^{\prime} O_{18}{ }^{\prime}$ than to $O_{15}{ }^{\prime} O_{16}{ }^{\prime}$, and $\beta_{2}>45^{\circ}$, at this time, the disc connecting rod needs to be retracted. Figure $7 \mathrm{c}$ shows the working process when the first contact point lies at the right side of the midpoint. The outer edge of the obstacle-avoiding disc contacts the obstacle at point 11 and leaves at point 12 . The center of obstacle-avoiding disc to $O_{19}{ }^{\prime} O_{20}{ }^{\prime}$ is farther than to $O_{15}{ }^{\prime} O_{16}{ }^{\prime}$, and $\beta_{3}=45^{\circ}$, at this time, the disc connecting rod does not need to be retracted. The retracted process is uncontrollable in Figure $7 \mathrm{~b}$, and the cutting area of UOAM around obstacle in Figure $7 \mathrm{c}$ is less than that of Figure 7a. To ensure the cutting quality, the first contact point (between the obstacle-avoiding disc and the obstacle) should be at the midpoint of $1 / 4$ arc on the right semi-circle of the obstacle-avoiding disc in advancing direction.

The working principle of the hydraulic profiling mechanism is shown in Figure 8. The width of the front and rear mounted frames should be less than the width of the tractor, thus, the length of the front and rear mounted frame is $1 \mathrm{~m}$. When UOAM is contracted, the median planes of the front and rear mounted frames coincide with each other. Through simple geometric calculation, $l_{3}=1.2 \mathrm{~m}$. The HSG40-25 type of hydraulic cylinder was selected (manufactured by Huixing Hydraulic Co., Ltd., Shandong, China).

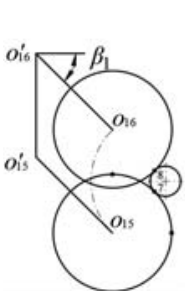

a. Midpoint

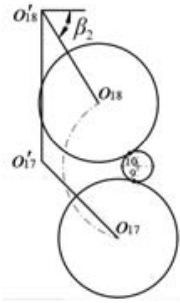

b. Midpoint left

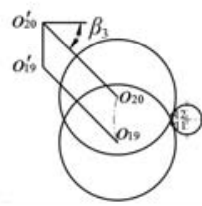

c. Midpoint right
Note: $\beta_{1}, \beta_{2}$, and $\beta_{3}$ are the angles between the disc connecting rod and the horizontal line, $\left({ }^{\circ}\right)$.

Figure 7 Positions of obstacle-avoiding disc at different contact points

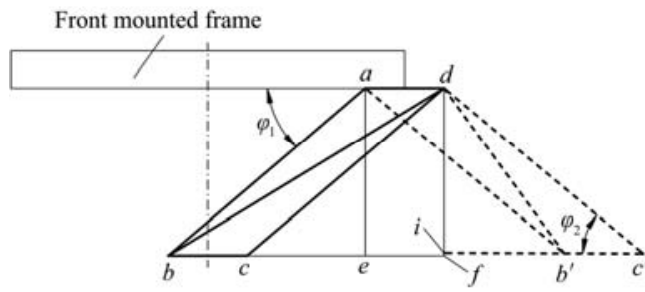

Note: $a b$ is the distance of two hinge points on the left moving arm, $\mathrm{m} ; c d$ is the distance of two hinge points on the right moving arm, $\mathrm{m}$; $a d$ is the distance of two hinge points on the front mounted frame, $\mathrm{m} ; b c$ is the distance of two hinge points on the rear mounted frame, $\mathrm{m} ; b d$ is the maximum length of the hydraulic cylinder, $\mathrm{m} ; \varphi_{1}$ is the angle between $a b$ and the horizontal line in the figure, $\left(^{\circ}\right)$; $\varphi_{2}$ is the angle between $c^{\prime} d$ and the horizontal line in the figure, $\left({ }^{\circ}\right)$; the parallelograms $a b c d$ and $a b^{\prime} c^{\prime} d$ indicate the hydraulic profiling mechanism at positions of contraction and extension, respectively.

Figure 8 Working principle of the hydraulic profiling mechanism

In Figure 8, the right triangle $b d f$, abe and $d i c^{\prime}$ meet the Pythagorean theorem. In parallelograms $a b c d$ and $a b^{\prime} c^{\prime} d, a d=b c$ $=b^{\prime} c^{\prime}, a b=c d=a b^{\prime}=c^{\prime} d . \quad d b^{\prime}, b^{\prime} c^{\prime}$ and $c^{\prime} d$ in triangle $d b^{\prime} c^{\prime}$ satisfy the law of cosines. The functional relationship of them is shown in Equation (2). It can be known from the parameters of the hydraulic cylinder that, $b d=0.82 \mathrm{~m}$. In the right triangle $b d f, f b=$ $0.7 \mathrm{~m}, d f=0.43 \mathrm{~m}$. In the right triangle $a b e, a e=d f=0.43 \mathrm{~m}, b e=$ $0.5 \mathrm{~m}$. It can be calculated that $a b=0.66 \mathrm{~m}, \angle \varphi_{1}=40.7^{\circ}$.

$$
c^{\prime} d^{2}+b^{\prime} c^{\prime 2}-2 c^{\prime} d \times b^{\prime} c^{\prime} \times \cos \varphi_{2}=d b^{\prime 2}
$$

It can be known from the hydraulic cylinder parameters that $d b^{\prime}=0.52 \mathrm{~m}$. According to Equation (2), $\angle \varphi_{2}=39^{\circ}$. Then, in the right triangle $d i c^{\prime}, i c^{\prime}=c^{\prime} d \times \cos \varphi_{2}=0.51 \mathrm{~m}$. By simple geometric calculation, $l_{4}=f b+i c^{\prime}-b c+l_{3}=2.21 \mathrm{~m}$. The maximum extension distance of the hydraulic profiling mechanism is $l_{4}-l_{3}=$ $1.01 \mathrm{~m}$.

The cutting process can be divided into two stages: normal cutting and obstacle-avoiding cutting. In the normal cutting process, the trajectory of the blade is a combination of linear (center of the obstacle-avoiding disc) and circular (cutting disc) motion. Taking the center point of the obstacle-avoiding disc as $O$, the horizontal direction to the right is the positive direction of $X$-axis, and the vertical direction forward is the positive direction of $Y$-axis, to form a rectangular plane coordinate system, as shown in Figure 9.

The movement equation of point $m_{1}$ is,

$$
\left\{\begin{array}{l}
X_{m_{1}}=r \cos \omega t \\
Y_{m_{1}}=r \sin \omega t+v t
\end{array}\right.
$$


where, $X_{m_{1}}$ is the value of point $m_{1}$ on $X$-axis, $\mathrm{m} ; Y_{m_{1}}$ is the value of point $m_{1}$ on $Y$-axis, $\mathrm{m} ; r$ is the rotation radius of the cutting disc, $\mathrm{m}$; $\omega$ is the rotation speed of the cutting disc, $\mathrm{rad} / \mathrm{s} ; t$ is working time, $\mathrm{s}$; $v$ is the advancing speed of UOAM, $\mathrm{m} / \mathrm{s}$.

The movement equation of point $n_{2}$ is,

$$
\left\{\begin{array}{l}
X_{n_{2}}=(r-l) \cos \left(\omega t-\frac{2 \pi}{k}\right) \\
Y_{n_{2}}=(r-l) \sin \left(\omega t-\frac{2 \pi}{k}\right)+v t
\end{array}\right.
$$

where, $X_{n 2}$ is the value of the point $n_{2}$ on $X$-axis, $\mathrm{m} ; Y_{n 2}$ is the value of the point $n_{2}$ on $Y$-axis, $\mathrm{m}$; $l$ is the cutting edge length of the blade, $\mathrm{m} ; k$ is the blade number.

Take the maximum values of point $m_{1}$ and point $n_{2}$ on $Y$-axis by taking the derivatives of $Y_{m_{1}}$ and $Y_{n_{2}}$ in Equations (3) and (4), that is,

$$
\begin{gathered}
Y_{m_{1} \max }=\frac{v}{\omega} \arccos \left(-\frac{v}{\omega r}\right)+r \sqrt{1-\left(\frac{v}{\omega r}\right)^{2}} \\
Y_{n_{2} \max }=\frac{2 \pi v}{k \omega}+\frac{v}{\omega} \arccos \left[-\frac{v}{\omega(r-l)}\right]+\sqrt{(r-l)^{2}-\frac{v^{2}}{\omega^{2}}}
\end{gathered}
$$

where, $X_{m_{1} \max }$ is the maximum value of the point $m_{1}$ on $Y$-axis, m; $Y_{n_{2} \max }$ is the maximum value of the point $n_{2}$ on $Y$-axis, $\mathrm{m}$.

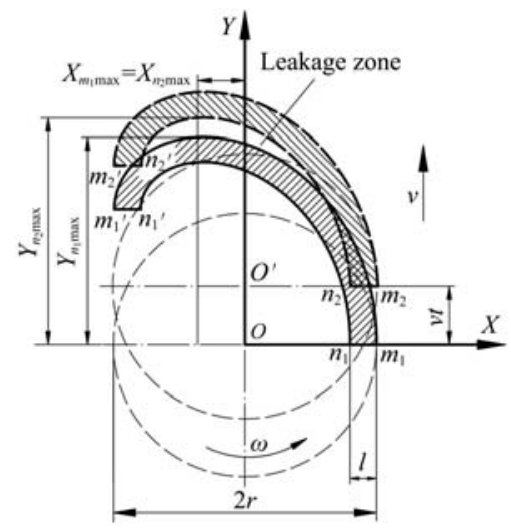

Note: $O$ and $O^{\prime}$ is the center point of the obstacle-avoiding disc before and after movement; $m_{1}, n_{1}$ are the outermost and innermost points of the first blade cutting edge; $m_{2}, n_{2}$ are the outermost and innermost points of the second blade cutting edge; the thick solid line area $\left(m_{1} m_{1}{ }^{\prime} n_{1}{ }^{\prime} n_{1}\right)$ and dashed line area $\left(m_{2} m_{2}{ }^{\prime} n_{2}{ }^{\prime} n_{2}\right)$ indicate the trajectories of the cutting edge of the first and second blades respectively; coordinate values $X_{m, \max }$ and $Y_{m, \max }$ indicate the highest point of curve $m_{1} m_{1}{ }^{\prime}$; coordinate values $X_{n_{2} \max }$ and $Y_{n_{2} \max }$ indicate the highest point of curve $n_{2} n_{2}{ }^{\prime} ; v$ is the advancing speed of the mower, $\mathrm{m} / \mathrm{s} ; t$ is working time, $\mathrm{s} ; \omega$ is the rotation speed of the cutting disc, $\mathrm{rad} / \mathrm{s} ; r$ is the rotation radius of the cutting disc, $\mathrm{m} ; l$ is the cutting edge length of the blade, $\mathrm{m}$.

Figure 9 Trajectory of blade cutting edge movement

To reduce the leakage rate, $Y_{m 1 \max }$ should be greater than $Y_{n 2 \max }$, which means

$$
Y_{m_{1} \max }-Y_{n_{2} \max } \geq 0
$$

Substitute Equations (5) and (6) into Equation (7), then, Equation (8) is obtained. It is the optimal kinematic model of the cutting disc in the normal cutting process.

$\sqrt{1-\frac{v^{2}}{\omega^{2} r^{2}}}-\sqrt{\left(1-\frac{l}{r}\right)^{2}-\frac{v^{2}}{\omega^{2} r^{2}}}+\frac{v}{\omega r}\left[\arccos \frac{v}{\omega(r-l)}-\arccos \frac{v}{\omega r}\right]$

$-\frac{2 \pi v}{k \omega r} \geq 0$

The advancing speed is positively related to the leakage rate and working efficiency, while the rotation speed of the cutting disc is inversely related to the leakage rate and has nothing to do with working efficiency. The gear selection of tractors for orchard farming is mainly between low-speed gears I and II. Low-speed gear I is used in high-power machines, and low-speed gear II is used in low-power machines. In this study, low-speed gear II of the tractor was chosen as the working power (tractor advancing speed was $0.44 \mathrm{~m} / \mathrm{s}$ ). The rotation diameter of the cutting disc should be less than the diameter of the obstacle-avoiding disc, and the rotation diameter of the cutting disc was $0.65 \mathrm{~m}$. The minimum rotation speed of the cutting disc stipulated in the national standard GB/T10938 ${ }^{[27]}$ was $2500 \mathrm{r} / \mathrm{min}$. Considering that GB/T10938 is mainly applied to large forage mowers with higher advancing speed, while the small volume UOAM was applied to the orchard with lower advancing speed ${ }^{[28,29]}$, the minimum rotation speed of the cutting disc of UOAM should be reduced. In order to cut weed smoothly, by referring to Reference [30], the blade linear velocity of $70 \mathrm{~m} / \mathrm{s}$ showed optimal performance. It can be calculated that $\omega=2058 \mathrm{r} / \mathrm{min}$. By referring to the type of hydraulic motor, set $\omega=2000 \mathrm{r} / \mathrm{min}$. Insert $v=0.44 \mathrm{~m} / \mathrm{s}, \omega=209.44 \mathrm{rad} / \mathrm{s}, r=0.325 \mathrm{~m}$, and $l=0.2 \mathrm{~m}$ into Equation (8), and the calculation result satisfies Equation (8).

In the obstacle-avoiding cutting process, the trajectory of the blade is a combination of circular (center of the obstacle-avoiding disc) and circular (cutting disc) motion. The process of obstacle-avoiding cutting was analyzed based on ADAMS software ${ }^{[31-33]}$. Constraints and drivers were added to the virtual prototype assembly in ADAMS ${ }^{[34]}$. The cylinders represent ground piles and trunks. The obstacles and the ground are connected by the fixed joint. Disc fixed bracket and the ground are connected by the translational joint. Revolute joints are used to connect the disc fixed bracket and disc connecting rod, disc connecting rod and obstacle-avoiding disc, obstacle-avoiding disc and cutting disc. The pair connection of point-curve connects the midpoint of the $1 / 4$ arc on the right semi-circle of the obstacle-avoiding disc and the obstacle circumference. The translational joint motion controls the advancing speed of the mower and the revolute joint motion controls the rotation speed of the cutting disc. Adding markers to the end points of the blade cutting edge (four markers totally, from Marker 1 to Marker 4). Set translational joint motion at $0.44 \mathrm{~m} / \mathrm{s}$, revolute joint motion at $2000 \mathrm{r} / \mathrm{min}$, and simulation step at $0.001 \mathrm{~s}$. Blade cutting edge trajectory in the obstacle-avoiding process is shown in Figure 10. In the ADAMS simulation process, each calculation step will generate a position point coordinate for the trajectories of the markers. For the convenience of analysis, the point coordinate data generated by ADAMS will be drawn in the form of the spline curve in AutoCAD software. Adjust the background color of the AutoCAD drawing zone to white and fill the cutting area of each blade cutting edge with black color. The results show that the cutting area of blade cutting edge is black, thus, there was no leakage in the cutting area.
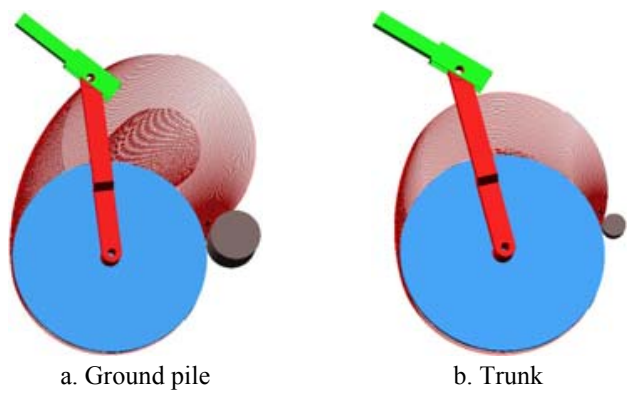

Figure 10 Trajectories of virtual prototype simulation

\subsection{Methods of field tests}

In March 2021, field tests were conducted in the Y-trellis pear 
orchards of Jiangsu Academy of Agricultural Sciences. The road of the orchard was flat. The trees were 6 years old $(6$ a), and planted $5 \mathrm{~m}$ in line spacing and $3 \mathrm{~m}$ in row spacing. Trellis height was $3 \mathrm{~m}$, height of the fixing rod was $0.5 \mathrm{~m}$, and the angle between the trellis plane and the ground was $45^{\circ}$. A YCX-504D type tractor (manufactured by Yueda Group Co., Ltd., Jiangsu, China) was selected in this study. The field test of UOAM is shown in Figure 11.

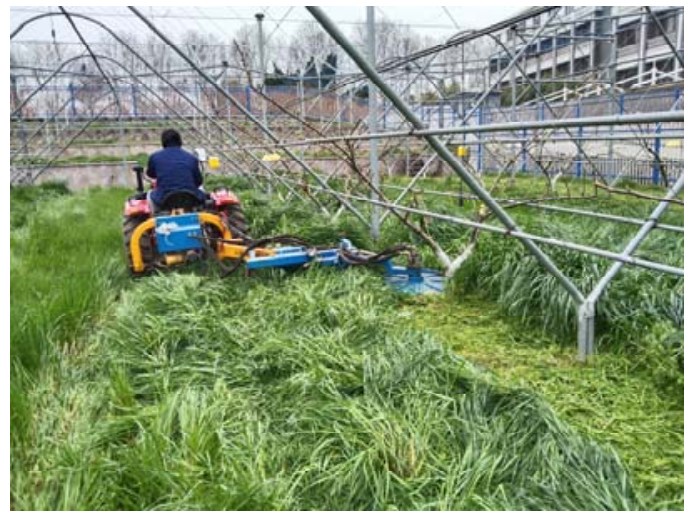

Figure 11 Field test of UOAM

Three treatments were tested, which were UOAM mowing, SCM mowing and manual weeding. Three test indexes were used to evaluate the tests: stubble cutting stability, leakage rate ${ }^{[27]}$, work efficiency and cost.

To prevent the blade from cutting the ground ${ }^{[12]}$, stubble cutting height of UOAM and SCM were set to $10 \mathrm{~cm}$. To reflect the stubble cutting stability of three treatments, the coefficient variation of the stubble cutting height in different sample points was calculated. Five sample points (sampling area of each point was $1 \mathrm{~m}^{2}$ ) were selected randomly in the mowing area, and five measuring points were arranged diagonally within each sample point. Measurements started from the ground, and the average height of five measurement points was the stubble cutting height of the sample point. The stubble cutting height, standard deviation, and coefficient variation were calculated, as shown in Equations (9)-(11).

$$
h=\frac{\sum_{i=1}^{n} h_{i}}{5}
$$

where, $h_{i}$ is the stubble cutting height of point $i, \mathrm{~cm} ; h$ is the stubble cutting height of each sample point, $\mathrm{cm}$.

$$
S_{h}=\sqrt{\frac{\sum_{i=1}^{5}\left(h_{i}-h\right)^{2}}{5}}
$$

where, $S_{h}$ is the standard deviation of the stubble cutting height, $\mathrm{cm}$.

$$
\mathrm{CV}=\frac{S_{h}}{h} \times 100 \%
$$

where, $\mathrm{CV}$ is the coefficient variation of the stubble cutting height, $\%$.

Leakage rate was used to evaluate the cutting quality of the machine. It was defined as the division of the weight of leakage weeds by the weight of weeds cut per unit area. The leakage rate is calculated by Equation (12). Since the rotation diameter of the cutting disc was less than obstacle-avoiding disc diameter, the weeds around the obstacle were not cut. Similarly, when the SCM was used, the operator will leave a safe area around the obstacle. During sampling, leakage rates between and around obstacles were measured separately. Three rows of pear trees in the field were selected for sampling, and the sampling area of each sample point was $1 \mathrm{~m}^{2}$. Three sample points between obstacles and three sample points around obstacles were selected in each row.

$$
\mathrm{LR}=\frac{G_{l}}{G_{t}} \times 100 \%
$$

where, LR is the leakage rate, $\% ; G_{l}$ is the weight of leakage weeds in $1 \mathrm{~m}^{2}, \mathrm{~g} ; G_{t}$ is the weight of weeds cut in $1 \mathrm{~m}^{2}, \mathrm{~g}$.

The working time of each treatment was recorded and converted to working efficiency. The profitable area of UOAM was calculated based on the working efficiency, so as to guide the orchard manager to make a decision. The profitable area of the machine is the minimum planting area required by the machine to replace labor in management costs. According to Equations (13)-(15), the profitable area can be calculated. When the planting area of crops is larger than the profitable area, the machine can bring about profits.

$$
q=\frac{p}{n_{y}}
$$

where, $q$ is the annual depreciation of one mower, Yuan; $p$ is the price of one mower, Yuan; $n_{y}$ is the depreciable life, year.

$$
c=\frac{c_{0} t}{t_{0}} \times \eta
$$

where, $c$ is the cost that can be saved by the mower by replacing manual weeding, Yuan $/ \mathrm{hm}^{2} ; c_{0}$ is the labor cost in an eight-hour day, Yuan; $t$ is the average manual weeding time per unit area, $\mathrm{h} / \mathrm{hm}^{2} ; t_{0}$ is the working hours $(8 \mathrm{~h})$ of three treatments in one day, $\mathrm{h} ; \eta$ is the proportion of time saved in mechanical weeding to manual weeding.

$$
A=\frac{q+c_{\mathrm{uml}}}{c}
$$

where, $A$ is the profitable area of one machine, $\mathrm{hm}^{2} ; c_{\text {uml }}$ is the use, maintenance and labor operation costs of the tractor for mower per year, Yuan.

\section{Results and discussion}

\subsection{Stubble cutting stability}

Stubble cutting height and its coefficient variation of three treatments are shown in Table 2. The average stubble cutting height of three treatments was $10.34 \mathrm{~cm}$ for UOAM, $8.33 \mathrm{~cm}$ for SCM and $2.16 \mathrm{~cm}$ for manual weeding. The average stubble cutting heights of the three treatments are different, which is related to their operation modes. The rotation diameter of UOAM was $0.65 \mathrm{~m}$, in this case, there are slopes and clods within the operation area. To prevent the mower from touching the soil and ensure smooth mowing operation, the stubble cutting height should be set to $10 \mathrm{~cm}$. Although the rotation diameter of SCM was relatively small, it also had the same problem of touching the soil, thus, the stubble cutting height was also set at $10 \mathrm{~cm}$. Since SCM mowing is highly affected by human factors, the operation result deviated far from the set value. In manual weeding, the operator is usually used to cutting off weeds with sickles near the root, so that the stubble cutting height is only about $2 \mathrm{~cm}$. There are some advantages in this way of weeding: the leaf buds of weeds are cut off and their growth is restricted for a long time, thus reducing the frequency of manual weeding. Stubble cutting height of UOAM was the closest to the set value, with a relative error of $3.4 \%$. The reason is that the path in the orchard was flat, and there were not 
many bumps in mowing. The stubble cutting height of SCM was lower than the set value, with a relative error of $16.7 \%$, which was bigger than that of UOAM, showing that the operation stability of SCM was lower than that of UOAM. The coefficient variation of stubble cutting height of the three treatments was: $6.14 \%$ for UOAM, $15.69 \%$ for SCM and $15.49 \%$ for manual weeding. The coefficient variation of stubble cutting height of UOAM was the smallest in three treatments. This is related to the mechanized operation of UOAM: the tractor of UOAM follows a fixed route and is more stable than SCM and manual weeding, in which the operator repeatedly moves around the obstacle. The coefficient variations of stubble cutting height of SCM and manual weeding were higher, showing that it was more difficult for the two treatments to ensure the uniformity of stubble cutting height than UOAM. SCM and manual weeding were carried out by the operator manually, and the stubble cutting height is subjectively controlled by the operator, therefore, the fatigue caused by long time operation will greatly affect the accuracy of weeding.

Table 2 Stubble cutting height $h$ and coefficient variation $C V$

\begin{tabular}{ccccc}
\hline $\begin{array}{c}\text { Sample point } \\
\text { number }\end{array}$ & Index & $\begin{array}{c}\text { UOAM } \\
\text { mowing }\end{array}$ & $\begin{array}{c}\text { SCM } \\
\text { mowing }\end{array}$ & $\begin{array}{c}\text { Manual } \\
\text { weeding }\end{array}$ \\
\hline \multirow{2}{*}{1} & $h / \mathrm{cm}$ & 10.50 & 7.44 & 2.74 \\
& $\mathrm{CV} / \%$ & 4.89 & 16.10 & 15.76 \\
\hline \multirow{2}{*}{3} & $h / \mathrm{cm}$ & 10.34 & 9.84 & 2.14 \\
& $\mathrm{CV} / \%$ & 5.63 & 15.95 & 13.74 \\
\hline \multirow{2}{*}{4} & $h / \mathrm{cm}$ & 9.88 & 8.16 & 1.74 \\
& $\mathrm{CV} / \%$ & 7.11 & 16.21 & 15.68 \\
\hline \multirow{2}{*}{5} & $h / \mathrm{cm}$ & 10.46 & 8.26 & 1.98 \\
& $\mathrm{CV} / \%$ & 6.94 & 14.92 & 14.78 \\
\hline \multirow{2}{*}{ Average } & $h / \mathrm{cm}$ & 10.52 & 7.94 & 2.20 \\
& $\mathrm{CV} / \%$ & 6.11 & 15.29 & 17.49 \\
\hline
\end{tabular}

\subsection{Leakage rate}

Leakage rate of UOAM and SCM are shown in Figure 12. Leakage rate of SCM in the same condition was higher than that of UOAM. The data fluctuation of the SCM was larger than that of UOAM. To analyze the leakage rate of UOAM and SCM accurately, the coefficient variation of leakage rate was calculated. The calculation method of coefficient variation was the same as that of stubble cutting stability, and the results are shown in Table 3. Leakage rate between obstacles was $0.21 \%$ for UOAM and $1.9 \%$ for SCM, showing that UOAM and SCM had the least leakage amount of weeds between obstacles. Leakage rate around obstacles was $4.64 \%$ for UOAM and $5.95 \%$ for SCM, higher than that between obstacles. The reason is that UOAM and SCM leave a certain safe zone around obstacles so that the mower would not cut the weeds around the trunk or ground pile. The coefficient variation of leakage rate was $7.38 \%$ for UOAM between obstacles, $14.41 \%$ for SCM between obstacles, $7.66 \%$ for UOAM around obstacles, and $9.2 \%$ for SCM around obstacles. SCM was carried out by the operator manually, and in SCM, the operator repeatedly moves around the obstacle, causing great errors. Therefore, the coefficient variation of SCM was higher than that of UOAM. The coefficient variation of leakage rate in SCM between obstacles was larger than that around obstacles, because the weight of leakage weeds between obstacles was far less than that around obstacles, and the influence of the change of leakage weeds in mowing is significantly greater than that around the obstacles.

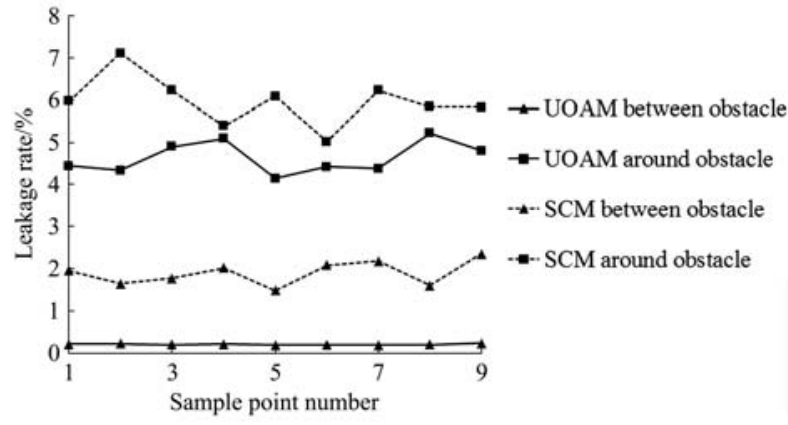

Figure 12 Leakage rate of each sample point

Table 3 Leakage rate $L R$ and coefficient variation CV

\begin{tabular}{ccccc} 
Treatment & Index & Between obstacles & Around obstacles & Average value \\
\hline \multirow{2}{*}{ UOAM mowing } & LR/\% & 0.21 & 4.64 & 2.42 \\
& CV/\% & 7.38 & 7.66 & 7.52 \\
\hline \multirow{2}{*}{ SCM mowing } & LR/\% & 1.90 & 5.95 & 3.93 \\
& CV/\% & 14.41 & 9.20 & 11.8
\end{tabular}

\subsection{Working efficiency and cost}

The working efficiency of the three treatments was tested in the field tests and the results are shown in Table 4. The working efficiency of UOAM was much higher than that of SCM and manual weeding, which was 4.44 times to SCM and 20 times to manual weeding. The price of UOAM is 5000 Yuan, with 5 years of depreciable life. The weeding times of pear orchard are 4 to 5 per year, the use, maintenance and labor operation costs of tractor for weeding is 800 Yuan per time, so the annual cost is calculated at 4000 Yuan. The labor cost is 120 Yuan in an eight-hour day, and manual weeding time per unit area is $50 \mathrm{~h} / \mathrm{hm}^{2}$. The total proportions of time saved by UOAM to the manual weeding were 95\%. According to Equations (13)-(15), the profitable area of UOAM was $7.02 \mathrm{hm}^{2}$. Since population aging in China nowadays has become more and more serious ${ }^{[35]}$, with a large number of farmers working in cities, the small-scale orchard farms have been replaced by large-scale modern fruit companies. SCM mowing and manual weeding, which are suitable for family farms, have been eliminated in industry. In such circumstances, mechanized UOAM is especially suitable for large-scale mechanized Y-trellis orchard management. Orchard managers can use a certain amount of UOAM according to their orchard planting area and the cost that they can afford.

Table 4 Working efficiency $E$ and profitable area $A$

\begin{tabular}{ccc}
\hline Treatment & $E / \mathrm{hm}^{2} \cdot \mathrm{h}^{-1}$ & $A / \mathrm{hm}^{2}$ \\
\hline UOAM mowing & 0.40 & 7.02 \\
SCM mowing & 0.09 & -- \\
Manual weeding & 0.02 & -- \\
\hline
\end{tabular}

\section{Conclusions}

1) In this study, a unilateral obstacle-avoiding mower was developed. The mower is composed of an obstacle-avoiding disc mechanism, a hydraulic profiling mechanism and a cutting disc mechanism. The diameter of the obstacle-avoiding disc was $0.7 \mathrm{~m}$, which could swing around the trunk or ground pile under the action of the spring mechanism. The piston movement of the hydraulic cylinder controls the working position of the obstacle-avoiding disc, and the maximum extension distance of the hydraulic profiling arm was $1 \mathrm{~m}$. Referring to the national standards and actual situation of orchards, the optimum parameters were determined as follows: working speed of $0.44 \mathrm{~m} / \mathrm{s}$, rotation 
speed of cutting disc of $2000 \mathrm{r} / \mathrm{min}$, blade number of 2, and cutting edge length of $0.2 \mathrm{~m}$.

2) Three treatments were tested in field tests, which were UOAM mowing, SCM mowing and manual weeding. Three indexes were used to evaluate the tests: stubble cutting stability, leakage rate, working efficiency and cost. The coefficient variation of stubble cutting height of UOAM was the smallest in three treatments, showing that the working stability of UOAM was better than the other two treatments. The leakage rate of UOAM was $2.42 \%$, and its coefficient variation was smaller than SCM. The working efficiency of UOAM was much higher than that of SCM and manual weeding, which was 4.44 times to SCM and 20 times to manual weeding. The profitable area of UOAM was $7.02 \mathrm{hm}^{2}$, showing that it was suitable for large-scale mechanized Y-trellis pear orchards.

\section{Acknowledgements}

This work was supported by the China Agriculture Research System of MOF and MARA (Grant No. CARS-28-21), Jiangsu Agricultural Science and Technology Innovation Fund (Grant No. CX(21)2025), Jiangsu Modern Agricultural Machinery Equipment and Technology Demonstration Extension Fund (Grant No. NJ2019-28).

\section{[References]}

[1] Wang C, Zeng A, He X, Song J, Herbst A, Gao W. Spray drift characteristics test of unmanned aerial vehicle spray unit under wind tunnel conditions. Int J Agric \& Biol Eng, 2020; 13(3): 13-21.

[2] Wang Z, He X, Li T, Huang M, Zhang Y, Xu L, et al. Evaluation method of pesticide droplet drift based on laser imaging. Transactions of the CSAE, 2019; 35(9): 73-79. (in Chinese)

[3] Gaines T, Duke S, Morran S, Rigon C, Tranel P, Küpper A, et al. Mechanisms of evolved herbicide resistance. Journal of Biological Chemistry, 2020; 295(30): 10307-10330.

[4] Arentoft B, Ali A, Streibig J, Andreasen C. A new method to evaluate the weed-suppressing effect of mulches: a comparison between spruce bark and cocoa husk mulches.Weed Research, 2013; 53(3): 169-175.

[5] Martinelli R, Monquero P, Fontanetti A, Conceicao P, Azevedo F. Ecological mowing: An option for sustainable weed management in young citrus orchards. Weed Technology, 2017; 31(2): 260-268

[6] Wu J, Zhang J, Qian J, Huang J. Intercropping grasses improve soil organic carbon content and microbial community functional diversities in Chinese hickory stands. Transactions of the CSAE, 2013; 29(20): 111-117. (in Chinese)

[7] Bai G, Zou C, Du S. Effects of self-sown grass on soil moisture and tree growth in apple orchard on Weibei dry plateau. Transactions of the CSAE, 2018; 34(3): 151-158. (in Chinese)

[8] Song Y, Zhang T, Fan G, Gao D, Wang Z, Gao X. Research progress of domestic and foreign growing grass technologies and cutting machines in orchard. Journal of Chinese Agricultural Mechanization, 2017; 38(5): 111-117. (in Chinese)

[9] Zhang B, Zhang H, Xiao Y, Wang P. The design of weeding machine allowing trees among plants. Journal of Agricultural Mechanization Research, 2018; 40(1): 63-67. (in Chinese)

[10] Wang L, Zhang B, Zhang H, Li G, Guo S, Liu X. The design equipment of allowing trees for weeding among plants. Journal of Agricultural Mechanization Research, 2018; 40(10): 69-74. (in Chinese)

[11] Xu L, Yu C, Liu W, Yuan Q, Ma S, Duan Z, et al. Optimal design on auto obstacle avoidance mechanism of intra-row weeder for trellis cultivated grape. Transactions of the CSAE, 2018; 34(7): 23-30. (in Chinese)

[12] Zhao Q. Design and experimental study of orchard avoidance rotary cultivator. Master dissertation. Tarim, China: Xinjiang Tarim University, 2017; 75p. (in Chinese)

[13] Zhang M. Design of obstacle avoidance system of orchard lawn mower based on binocular vision technology. Master dissertation. Baoding, China: Hebei Agricultural University, 2019; 63 p. (in Chinese)

[14] Lei X, Lyu X, Zhang M, Shen Q, Lu D, Ma Z, et al. Design and test of orchard unilateral combine mower. International Agricultural Engineering Journal, 2020; 29(4): 157-167.

[15] Muhammad Z, Masakazu K. Weed management and economic analysis of a robotic lawnmower: A case study in a Japanese pear orchard. Agriculture-Basel, 2021; 11(2): 113. doi: 10.3390/agriculture11020113.

[16] Mia M, Massetani F, Murri G, Facchi J, Monaci E, Amadio L, et al Integrated weed management in high density fruit orchards. Agronomy-Basel, 2020; 10(10): 1492. doi: 10.3390/agronomy10101492.

[17] Mia M, Monaci E, Murri G, Massetani F, Facchi J, Neri D. Soil nitrogen and weed biodiversity: An assessment under two orchard floor management practices in a nitrogen vulnerable zone in Italy. Horticulturae, 2020; 6(4): 96. doi: 10.3390/horticulturae6040096.

[18] Martinelli R, Monquero P, Fontanetti A, Conceição P, Azevedo F. Ecological mowing: An option for sustainable weed management in young citrus orchards. Weed Technology, 2017; 32(2): 1-9.

[19] Granatstein D, Andrews P, Groff A. Productivity, economics, and fruit and soil quality of weed management systems in commercial organic orchards in Washington State, USA. Organic Agriculture, 2014; 4(3): 197-207.

[20] Choi J, Gu M, Choi J, Han J, Yim S, Kim Y, et al. Growth and fruit production of Asian pear trees grown on Y-, T-, and Vase-training systems. Horticulture Environment \& Biotechnology, 2014; 55(1): 1-18.

[21] Choi J, Choi J, Han J, Yim S, Jung S, Choi H. Comparision of growth characteristics and productivity of young trees of a new cultivar 'Manpungbae' trained to trellis systems. Horticultural Science and Technology, 2017; 35(4): 393-401.

[22] Jiang H, Zhang Z, Zhu X, Li Y. A new barrier material for preventing weed proliferation in plantation of young tea bBushes. Acta Tea Sinica, 2017; 58(4): 189-192. (in Chinese)

[23] Hu F, Yang H, Sheng Z, Luo H, Zhai X, Shang J, et al. Research progress of weed control in tea garden. Journal of Henan Agricultural Sciences, 2018; 47(10): 7-11. (in Chinese)

[24] Yang Q, Lin J, Li X, Yan Z, Sheng B. Effects of four kinds of tree type on pear growth and fruit quality. Jiangsu Agricultural Sciences, 2007; (6) 150-152. (in Chinese)

[25] Zou J, Li C, Lyu Y, Li J. Thinking and suggestion of developing professional orchard wheeled tractors in China. Tractor \& Farm Transporter, 2017; 44(5): 1-4. (in Chinese)

[26] Zhu X, Lyu K, Song C, Zhao G. Study on the influence of cylinder helical spring's geometrical parameters on spring constant based on ABAQUS. Machine Design and Research, 2015; 31(4): 95-98. (in Chinese)

[27] GB/T 10938-2008. Inspection and Quarantine of the People's Republic of China (AQSIQ). Rotary mowers, 2008. (in Chinese)

[28] Zhao M, Zhang N, Yang T, Shi Y. Design and experiment of virtual Ppototype of double disc mower cutter. Transactions of the CSAM, 2014; 45(8): 101-105. (in Chinese)

[29] Wu B, Wang D, Wang G, Fu Z, Kang S. Optimization and experiments of cut-condition device working parameter on mower conditioner. Transactions of the CSAM, 2017; 48(10): 76-83. (in Chinese)

[30] Fu Z, Wang D, Li W, Huang Y, Zhu R. Design and experiment of two-disc rotary mower of Alfalfa. Transactions of the CSAM, 2018; 49(S1): 214-220. (in Chinese)

[31] Song Z, Song H, Yan Y, Li Y, Gao T, Li F. Optimizing design on knife section of reciprocating cutter bars for harvesting cotton stalk. Transactions of the CSAE, 2016; 32(6): 42-49. (in Chinese)

[32] Liu H, Wang P, Gai G, Xiang B. Analysis and parameter solution of injection type no-till seeding into hole trajectory based on five-bar mechanism. Transactions of the CSAE, 2017; 33(8): 21-29. (in Chinese)

[33] $\mathrm{Yu} \mathrm{Z}$, Huai S, Wang W. Leakage rate and optimization of working parameters for cylinder pickup collector based on spring-finger trajectory. Transactions of the CSAE, 2018; 34(4): 37-43. (in Chinese)

[34] Xing J, Xyu L, Yuan Q, Ma S, Yyu C, Duan Z. Design and test of pushing device for dent corn seeds directional sowing. Transactions of the CSAE, 2018; 34(17): 9-15. (in Chinese)

[35] Zheng Y, Jiang S, Chen B, Lyu H, Wan C, Kang F. Review on technology and equipment of mechanization in hilly orchard. Transactions of the CSAM, 2020; 51(11): 1-20. (in Chinese) 